\title{
OPEN Prospective investigation of polyomavirus infection and the risk of adult glioma
}

\author{
Kathleen M. Egan ${ }^{1 凶}$, Youngchul Kim², Noemi Bender ${ }^{3}$, James M. Hodge ${ }^{4}$, Anna E. Coghill ${ }^{1}$, \\ Stephanie A. Smith-Warner ${ }^{5}$, Dana E. Rollison ${ }^{1}$, Lauren R. Teras ${ }^{4}$, Tom K. Grimsrud ${ }^{6}$ \& \\ Tim Waterboer ${ }^{3}$
}

Glioma is an aggressive primary tumor of the brain with a poorly understood etiology. We studied the association of 4 human polyomaviruses (HPyV)—JC virus (JCV), BK virus (BKV), human polyomavirus 6 (HPyV6), and Merkel cell polyomavirus (MCPyV) with glioma risk within the Cancer Prevention Study II in the US (CPS-II) and the Janus Serum Bank in Norway. Cohort participants subsequently diagnosed with glioma from the CPS-II $(n=37)$ and Janus Serum Bank $(n=323)$, a median of 6.9 and 15.4 years after blood collection, respectively, were matched to individual controls on age, sex, and date of blood draw. Serum antibodies to the major viral capsid protein (VP1) were used to establish infection history for each polyomavirus. Odds ratios (ORs) and 95\% confidence intervals (Cls) were estimated using conditional logistic regression. In the Janus Serum Bank, MCPyV infection was associated with a higher risk of glioma overall (OR: 1.56; 95\% CI 1.10, 2.19). A modest, nonsignificant positive association with MCPyV infection was also observed in CPS-II (OR: 1.29; 95\% CI 0.54, 3.08). In both cohorts, glioma risk was not significantly related to infection with JCV, BKV or HPyV6. The present study suggests that MCPyV infection may increase glioma risk.

Malignant glioma is an aggressive primary neoplasm of the brain with poorly understood etiology ${ }^{1}$. Risk factors include advancing age, male gender, European ancestry ${ }^{2}$, inherited genetic factors ${ }^{3,4}$, taller height ${ }^{5}$, and an older age at menarche in women ${ }^{6}$. Ionizing radiation is the only well-validated environmental risk factor ${ }^{7}$. A reduced incidence of glioma is observed in persons with atopy ${ }^{8,9}$ or with elevated prediagnostic levels of the immune biomarker IgE $\mathrm{E}^{10-12}$, suggesting a role for immune function in glioma and consistent with a potential role for infection in the onset of these tumors ${ }^{13}$. A wide range of infections cross the blood-brain-barrier ${ }^{14}$ and are suspected to play a role in neuroinflammation and may contribute to neurodegenerative disease ${ }^{15}$ and neurological brain tumors ${ }^{16}$. While varicella zoster virus (VZV), a herpes virus that causes chicken pox and shingles, has consistently been linked to a reduced risk of glioma ${ }^{17-19}$, epidemiologic research on the role of other viruses in glioma remains limited.

Polyomaviruses (PyVs) are small, non-enveloped DNA viruses that exhibit the capacity to mediate cell transformation and tumorigenesis in different model systems ${ }^{20}$. A total of 14 PyVs are known to infect humans (human PyV, HpyV). Several of the HPyVs are neurotropic and/or have been linked to cancer in humans or other animals ${ }^{21,22}$. JC virus (JCV $)^{23}$ and BK virus (BKV) ${ }^{24}$ have been postulated to play a role in brain tumors ${ }^{25}$. JCV is the cause of progressive multifocal leukoencephalopathy ${ }^{26}$, a fatal demyelinating disease of the central nervous system. BKV is the causal agent in polyomavirus-associated nephropathy that occurs in patients undergoing immunosuppressive therapy. Both viruses are highly oncogenic when injected into the brain of experimental animals ${ }^{25}$. Merkel cell polyomavirus $(\mathrm{MCPyV})^{27}$, is the only known oncogenic PyV in humans and is the postulated cause of Merkel cell carcinomas (MCC) of the $\operatorname{skin}^{28}$. A raccoon PyV (RacPyV) closely related phylogenetically to $\mathrm{MCPyV}$ has been found to cause glioma-like tumors in raccoons ${ }^{29}$. The International Agency for Research on Cancer classifies Merkel cell polyomavirus (MCPyV) as a probable carcinogen whereas

\footnotetext{
${ }^{1}$ Department of Cancer Epidemiology, H. Lee Moffitt Cancer Center and Research Institute, 12902 Magnolia Drive, Tampa, FL 33612, USA. '2Department of Biostatistics, H. Lee Moffitt Cancer Center and Research Institute, Tampa, FL 33612, USA. ${ }^{3}$ Infections and Cancer Epidemiology, German Cancer Research Center (Deutsches Krebsforschungszentrum, DKFZ), 69120 Heidelberg, Germany. ${ }^{4}$ Department of Population Science, American Cancer Society, Atlanta, GA 30303, USA. ${ }^{5}$ Departments of Nutrition and Epidemiology, Harvard T.H. Chan School of Public Health, Boston, MA 02115, USA. ${ }^{6}$ Department of Research, Cancer Registry of Norway, 0379 Oslo, Norway. ${ }^{\circledR}$ email: kathleen.egan@moffitt.org
} 


\begin{tabular}{|c|c|c|c|c|c|c|c|c|c|c|}
\hline & \multicolumn{4}{|c|}{ Cancer Prevention Study II } & \multicolumn{6}{|c|}{ Janus Serum Bank } \\
\hline & \multicolumn{2}{|l|}{ All } & \multicolumn{2}{|l|}{ GBM } & \multicolumn{2}{|l|}{ All } & \multicolumn{2}{|l|}{ GBM } & \multicolumn{2}{|l|}{ nonGBM } \\
\hline & Cases & Controls & Cases & Controls & Cases & Controls & Cases & Controls & Cases & Controls \\
\hline All & 37 & 74 & 27 & 54 & 323 & 323 & 196 & 196 & 127 & 127 \\
\hline Male & $17(46 \%)$ & $34(46 \%)$ & $13(48 \%)$ & $26(48 \%)$ & $219(67 \%)$ & $219(67 \%)$ & $141(72 \%)$ & $141(72 \%)$ & $78(61 \%)$ & $78(61 \%)$ \\
\hline $\begin{array}{l}\text { Median age } \\
\text { at blood draw } \\
\text { (range) }\end{array}$ & $71(59-77)$ & $71(59-78)$ & $71(59-77)$ & $71(59-78)$ & $41(19-67)$ & $41(19-68)$ & $41(19-67)$ & $41(19-68)$ & $41(19-67)$ & $41(19-66)$ \\
\hline $\begin{array}{l}\text { Median year } \\
\text { of blood col- } \\
\text { lection (range) }\end{array}$ & $\begin{array}{l}2000 \\
(1999-2001)\end{array}$ & $\begin{array}{l}2000 \\
(1999-2001)\end{array}$ & $\begin{array}{l}2000 \\
(1998-2001)\end{array}$ & $\begin{array}{l}2000 \\
(1998-2001)\end{array}$ & $\begin{array}{l}1986 \\
(1972-1991)\end{array}$ & $\begin{array}{l}1986 \\
(1972-1991)\end{array}$ & $\begin{array}{l}1986 \\
(1972-1991)\end{array}$ & $\begin{array}{l}1986 \\
(1972-1991)\end{array}$ & $\begin{array}{l}1986 \\
(1972-1991)\end{array}$ & $\begin{array}{l}1986 \\
(1972-1991)\end{array}$ \\
\hline $\begin{array}{l}\text { Median years } \\
\text { from blood } \\
\text { draw to } \\
\text { glioma diag- } \\
\text { nosis (range) }\end{array}$ & $6.9(3.4-13.0)$ & na & $6.8(3.4-11.5)$ & $\mathrm{Na}$ & $15.4(5.1-34.9)$ & na & $16.4(5.1-35)$ & na & $14.6(5.1,35.0)$ & na \\
\hline
\end{tabular}

Table 1. Descriptive characteristics of nested case-control studies of Polyomaviruses and glioma risk: Cancer Prevention Study II and Janus Serum Bank.

BKV and JCV are classified as possible carcinogens ${ }^{30}$ based on "sufficient evidence in experimental animals" but "inadequate evidence of carcinogenicity in humans".

The role of polyomavirus infection in relation to glioma risk in humans is unknown. In the only prospective study to date ${ }^{31}$, antibodies to JCV, BKV, and simian virus 40 (SV40) measured in serum collected 1-22 years before glioma diagnosis were evaluated for association with incident glioma. Glioma cases $(n=44)$ and age-, gender- and race-matched controls $(n=88)$ were identified from participants of two specimen banks in Washington County, Maryland. The study detected no association with SV40. A nonsignificantly positive association was found for JCV (OR: 1.46), and an inverse association was found for BKV (OR: 0.66), with suggestively stronger but nonsignificant associations reported when restricting to grade IV glioblastomas (GBM) (ORs of 2.38 and 0.53 , respectively).

Using a nested case-control design within two prospective cohort studies with biobanked collected blood, the Janus Serum Bank and the Cancer Prevention Study II (CPS-II) Nutrition cohort, we conducted an exploratory investigation of 4 polyomaviruses, JCV, BKV, HPyV6 and MCPyV, in relation to glioma risk. A multiplex assay was used to detect serum antibodies to the major capsid proteins (VP1) of each virus. To avoid potential bias in results from effects of preclinical disease on serum antibody titers, the study was restricted to cases with blood collected a minimum of 3 years (in the CPS-II) or 5 years (in the Janus Serum Bank) prior to glioma diagnosis.

\section{Methods}

Study populations. Data from two cohorts were included in the present study: (1) the Cancer Prevention Study-II (CPS-II) Nutrition cohort, a US prospective study ${ }^{32}$; and (2) the Janus Serum Bank, a population-based prospective study based in Norway ${ }^{33}$. Baseline characteristics of participants from each cohort are shown in Table 1. Incident primary intracranial glioma cases (ICD9 and 10 topography codes: 191 and C71, respectively) were comprised of WHO grade IV glioblastomas (GBM) (ICD-O-3 histology code: 9440-9441), and lower grade gliomas ('nonGBM')(ICD-O-3 histology codes: 9380, 9382, 9400-01, 9410-11, 9420, 9424-25, 9450-9451) ) $^{34-36}$. In CPS-II, among the 32,609 cancer-free participants that provided a blood sample between 1998 and 2001 who were followed through the end of 2013, 37 glioma cases diagnosed a minimum of 3 years after sample collection were included in the present study. For each case, we randomly selected two controls from participants who provided a blood sample, and were alive and had no personal history of cancer (excluding basal and squamous cell carcinoma) as of the diagnosis date of the case. Each control was individually matched to its case on birth date within 1 year, sex, and date of blood draw within 6 months.

In the Janus Serum Bank, glioma cases and controls were identified from a previous nested case-control study of glioma ${ }^{12}$; a total of 323 glioma cases diagnosed a minimum of 5 years after blood collection were included in the present analysis. Each control was individually matched to its case on birth date within 2 years, sex, date of blood draw within 12 months, and county of residence, and was alive and free from any cancer except basal and squamous cell carcinoma on the date of glioma diagnosis of the case subject. All subjects were of European ancestry.

All research was performed in accordance with the human subjects' protection principles (Declaration of Helsinki), and the study was approved by the ethical review board of the Moffitt Cancer Center and from both participating cohorts (CPSII-NC: Emory University IRB \#00045780; Janus: Regional Committees for Medical and Health Research Ethics, Application 9821, \#2017/2140/ REK-s-o-B). All participants of the CPSII-NC provided written informed consent at the time of blood draw. As described previously ${ }^{37}$, Janus Serum Bank donors gave broad verbal consent (1973-1992) or provided explicit written informed consent (1997-2004) for use of samples for cancer research, in accordance with Norwegian legal requirements over time. The Norwegian Data Protection Authority has approved use of Janus data and samples collected between 1972 and 2004, while requiring that donors are free to unconditionally withdraw their consent at any time. All research projects using Janus specimens and data from the Cancer Registry of Norway also need approval from a Regional Committee for Medical and Health Research Ethics. 
Multiplex serological assays. Multiplex serological analyses to measure antibodies to the viral proteins were conducted at the German Cancer Research Center (Deutsches Krebsforschungszentrum, DKFZ) in Heidelberg, Germany. This method allows the simultaneous measurement of antibody responses to multiple proteins in biologic samples ${ }^{38}$. Polyomaviruses lead to strong and reproducible antibody responses to the major capsid protein VP1 $1^{39,40}$, a sensitive cumulative marker of past or present infection. For the current study, a prediagnostic plasma sample was obtained from each case and control from both participating cohort studies and shipped to the lab in Heidelberg for the analysis of serological markers of infection. Serological analyses were performed by fluorescent bead-based multiplex serology as previously described ${ }^{38-41}$. Briefly, the method is based on a glutathione S-transferase (GST) capture assay combined with fluorescent-bead (Luminex) technology. Proteins of interest are fused with an N-terminal GST domain. These recombinant GST-VP1 fusion proteins are affinity-purified in situ through binding to glutathione casein-coated fluorescence labelled polystyrene beads. Each fusion protein is bound to a spectrally distinct bead set (SeroMap, Luminex). The bead mix is then incubated in 96-well plates with participant plasma. Bound antibodies were detected with biotinylated triple (IgG, $\operatorname{IgA}, \operatorname{IgM})$ goat anti-human secondary antibody and streptavidin-R phycoerythrin reporter conjugate. A Luminex analyzer was used to identify the internal color of the individual beads and to quantify their reporter fluorescence (expressed as median fluorescence intensity (MFI)) as a measure of viral antibody titer. GST only (i.e. without viral antigen fusion component) served for background determination (i.e., negative control). Auto-fluorescence of each bead set and background reactions resulting from binding of secondary reagents were determined in one well per plate without human serum. Mean background values were subtracted from raw antibody output to determine antigen-specific reactivity (i.e., unit of statistical analysis). The serological analyses included the viral major capsid protein 1 (VP1) of four human polyomaviruses (JCV, BKV, HPyV6 and MCPyV). All samples from both cohorts were analyzed in a single laboratory batch avoiding measurement error otherwise introduced by the need for a bridging panel to normalize results across studies. Laboratory personnel were blinded to casecontrol status.

Statistical analysis. Odds Ratios (OR) and 95\% Confidence Intervals (CI) for associations of PyV infection and glioma risk were calculated using conditional logistic regression. All models were inherently adjusted for matching factors. We considered the association of glioma with seroprevalence (i.e., the presence or absence of VP1 antibodies) of each of the four HPyVs, with seropositivity for each HPyV defined as virus-specific VP1 antibody level $\geq 250 \mathrm{MFI}^{41}$. In Janus, associations of glioma with viral markers were considered overall, and according to glioma grade including WHO grade IV GBM $(\mathrm{n}=196)$ and all lower glioma grades, combined $(\mathrm{n}=127)$ including 56 astrocytomas (ICD-O-3: 9400-01, 9410-11, 9420, 9424-25), 27 oligodendrogliomas (9450 and 9451), 24 astrocytic tumors (9380) and 20 mixed gliomas (9382). (Data were too sparse to examine associations with individual lower grade tumors in Janus, and with nonGBMs ( $\mathrm{n}=10$ cases) in CPS-II.) In the Janus Serum Bank (in which larger numbers permitted an evaluation of dose response), we examined associations according to increasing MFI as a measure of viral burden. Tertiles of MFI among seropositive subjects were compared to a seronegative referent (i.e., $<250 \mathrm{MFI}$ ), with cutpoints established in seropositive controls. For JCV, tertile boundaries were 253-598, 601-1352, and 1365-14,967 for tertiles 1, 2, and 3, respectively; these figures were 251-1095, 1111-3695, and 3703-18,864, respectively, for BKV; 255-3052, 3069-5769, and 5774-18,637, respectively, for HPyV6; and 251-2837, 2846-6327, and 6346-17,802, respectively, for MCPyV.

Disclaimer. The views expressed here are those of the authors and do not necessarily represent the views of the American Cancer Society or the American Cancer Society-Cancer Action Network.

\section{Results}

The analyses were based on 37 glioma cases (27 GBMs) and 74 controls from CPS-II and 323 glioma cases (196 GBMs) and 323 controls from the Janus Serum Bank (Table 1).

In the CPS-II, approximately half of the cases and controls were male (46\%) and the median age at blood collection was 71 years (range 59-77 years). Year of blood collection ranged from 1999 to 2001 (median: 2000). Glioma cases were diagnosed between 2002 and 2013. The median interval between blood collection and glioma diagnosis was 6.9 years and ranged from 3.4 years to 13.0 years. In the Janus Serum Bank, a majority of the cases were male (67\%) and the median age at blood collection was 41 years (range 19-67 years), with a tight distribution on age (interquartile range in age: 39.8-42.6 years). Year of blood draw ranged from 1972 to 1991 (median: 1983). Glioma cases were diagnosed between 1980 and 2009. The median interval between blood collection and glioma diagnosis was 15.4 years and ranged from 5.1 to 34.9 years. In both studies, controls were similar to cases on age at blood draw, gender, and year of blood draw as these were matching factors. In CPS-II, the median age and interquartile range (IQR) at glioma diagnosis was 79 (75-81) and 76 (73-78), in males and females, respectively. In the Janus Serum Bank, in which participants were younger at enrollment, the median age and IQR of cases at glioma diagnosis for males and females were 57.1 (50.4-63.3) and 56.3 (52.1-60.3), respectively.

Seroprevalence of antibody markers among controls was $51 \%$ and $57 \%$ for JCV; $64 \%$ and $62 \%$ for MCPyV; $83 \%$ and $78 \%$ for BKV; and 77\% and 80\% for HPyV6, in the CPS-II and Janus Serum Bank, respectively, similar to seroprevalences reported for these PyVs in immunocompetent populations from different continents ${ }^{21,41-46}$.

In the Janus Serum Bank, infection with MCPyV was associated with a significantly increased risk of all gliomas combined (OR: 1.56; 95\% CI 1.10-2.19) (Table 2) and for overall glioma risk in men (OR: 1.59; 95\% CI 1.03-2.44) (not shown) ); positive associations of similar magnitude were observed for GBM (OR: 1.53 ; $95 \%$ CI 0.99-2.36) and nonGBM (OR: 1.60; 95\% CI 0.92-2.8), and for overall glioma risk in women (OR: 1.50; 95\% CI $0.85-2.64$ ) (not shown), although none were statistically significant due to more limited case numbers. A 


\begin{tabular}{|c|c|c|c|c|c|c|c|c|}
\hline \multirow[b]{2}{*}{ Virus } & \multicolumn{4}{|c|}{ Cancer Prevention Study II } & \multicolumn{4}{|l|}{ Janus Serum Bank } \\
\hline & $\begin{array}{l}\text { Cases seropositive/ } \\
\text { seronegative }\end{array}$ & $\begin{array}{l}\text { Controls seropositive/ } \\
\text { seronegative }\end{array}$ & OR & $95 \%$ CI & $\begin{array}{l}\text { Cases seropositive/ } \\
\text { seronegative }\end{array}$ & $\begin{array}{l}\text { Controls seropositive/ } \\
\text { seronegative }\end{array}$ & OR & $95 \%$ CI \\
\hline BKV & $31 / 6$ & $61 / 13$ & 1.09 & $0.39-3.03$ & $259 / 64$ & $250 / 73$ & 1.18 & $0.81-1.73$ \\
\hline JCV & $16 / 21$ & $41 / 33$ & 0.57 & $0.24-1.36$ & $166 / 157$ & $182 / 141$ & 0.82 & $0.60-1.12$ \\
\hline HPyV6 & $28 / 9$ & $57 / 17$ & 0.93 & $0.39-2.25$ & $258 / 65$ & $259 / 64$ & 0.98 & $0.67-1.44$ \\
\hline $\mathrm{MCPyV}$ & $25 / 12$ & $46 / 28$ & 1.29 & $0.54-3.08$ & $231 / 92$ & $201 / 122$ & 1.56 & $1.10-2.19$ \\
\hline
\end{tabular}

Table 2. Association of polyomavirus seroprevalence with glioma risk in the Cancer Prevention Study II and Janus Serum Bank. Analyses based on 37 glioma cases (27 GBMs) and 74 matched controls for CPS-II and 323 glioma cases (196 GBMs and 127 nonGBMs) and 323 matched controls in Janus Serum Bank. Referent group in all analyses comprised of seronegative (median fluorescence intensity $<250$ ) individuals. ORs and CIs were conditioned on the following matching factors: birth date within 1 year, sex, and date of blood draw within 6 months for CPSII; and age within 2 years, sex, county of residence, and date of blood collection within 12 months for Janus. BKV BK virus, JCV JC virus, HpyV6 Human Polyomavirus 6, MCPyV Merkel Cell Polyomavirus, GBM glioblastoma, OR odds ratio, CI confidence interval.

\begin{tabular}{|c|c|c|c|c|c|c|c|c|c|c|c|}
\hline \multirow[b]{3}{*}{ Virus } & \multicolumn{11}{|c|}{ Median Fluorescence Intensity of PyV } \\
\hline & \multirow{2}{*}{\begin{tabular}{|l|} 
Referent \\
MFI \\
\end{tabular}} & \multicolumn{3}{|c|}{ Tertile1 } & \multicolumn{3}{|c|}{ Tertile2 } & \multicolumn{3}{|l|}{ Tertile3 } & \multirow[b]{2}{*}{ p.trend } \\
\hline & & mMFI & OR & CI & mMFI & OR & CI & mMFI & OR & CI & \\
\hline BKV & $<250$ & 596 & 1.19 & $0.77-1.85$ & 2,239 & 1.33 & $0.82-2.14$ & 6,222 & 1.07 & $0.67-1.70$ & 0.761 \\
\hline JCV & $<250$ & 388 & 0.73 & $0.48-1.13$ & 914 & 0.79 & $0.52-1.22$ & 2,361 & 0.96 & $0.61-1.49$ & 0.579 \\
\hline HPyV6 & $<250$ & 1,389 & 1.11 & $0.68-1.82$ & 4,476 & 0.87 & $0.55-1.37$ & 8,118 & 1.01 & $0.64-1.58$ & 0.798 \\
\hline $\mathrm{MCPyV}$ & $<250$ & 1,158 & 1.73 & $1.12-2.68$ & 4,814 & 1.34 & $0.86-2.07$ & 8,596 & 1.63 & $1.04-2.56$ & 0.052 \\
\hline
\end{tabular}

Table 3. Association of Polyomavirus seroprevalence and antibody titer with glioma risk in the Janus Serum Bank. Referent group in all analyses is comprised of seronegative individuals, i.e., MFI $<250$. Median MFI in reference group is 110.5 for BKV; 81.0 for JCV; 9.0 for HPyV6; and 39.0 for MCPyV. Tertile cutpoints in the JANUS Serum Bank established among seropositive individuals. ORs and CIs were conditioned on the following matching factors: 2-year age interval, sex, county of residence, and date of blood collection within 12 months. BKV BK virus, JCV JC virus, HpyV6 Human Polyomavirus 6, MCPyV Merkel Cell Polyomavirus, $P y V$ polyoma virus, $m M F I$ median value of the median fluorescence intensity in each tertile, OR odds ratio, $C I$ confidence interval.

modest and non-significant positive association with MCPyV infection was also observed in CPS-II (Table 2) for all gliomas combined (OR: 1.29; 95\% CI 0.54-3.08).

In the CPS-II and Janus Serum Bank, the risk for all gliomas combined was not significantly related to seroprevalence of BKV (ORs: 1.09 (95\% CI 0.39-3.03) and 1.18 (95\% CI 0.81-1.73), respectively), JCV (ORs: 0.57 (95\% CI 0.24-1.36) and 0.82 (95\% CI 0.60-1.12), respectively), or HPyV6 (ORs: 0.93 (95\% CI 0.39-2.25) and 0.98 (95\% CI 0.67-1.44), respectively) (Table 2). Results for the 3 viral markers were similarly nonsignificant in both cohorts when restricting to GBM, and in the Janus Serum Bank when restricting to nonGBM (not shown). (Data were too sparse in CPS-II to evaluate associations for nonGBM, $\mathrm{n}=10$ cases.) All results for these 3 PyVs were similarly nonsignificant when considered separately in males and females (not shown).

We examined cross-reactivity between the 4 examined $\mathrm{PyVs}^{41}$ in the Janus Serum Bank and found modest correlations in antibody titers ranging from $\mathrm{r}=0.082(p$-value $=0.035)$ for the correlation of BKV with HPyV6, to $\mathrm{r}=0.167$ ( $p$-value $<0.001$ ) for the correlation of MCPyV with HPyV6. Therefore, in the Janus Serum Bank we examined associations of glioma with seroprevalence of each PyV adjusted for seroprevalence of the other PyVs and all results were essentially unchanged (not shown). For example, the odds ratio for MCPyV infection was 1.56 (95\% CI 1.10-2.19) in the unadjusted model and 1.61 (95\% CI 1.13-2.28) in the model adjusted for seroprevalence of BKV, JCV and HPyV6.

When examining risk according to tertiles of antibody levels to BKV, JCV, and HPyV6 in the Janus Serum Bank, no significant trends in risk emerged for all gliomas combined ( $p$-value trends $=0.761,0.579$ and 0.798 , respectively) (Table 3), or among GBMs and nonGBMs when considered separately (data not shown). For $\mathrm{MCPyV}$, a positive association of borderline significance was observed with increasing titer in gliomas overall $(p$-value trend $=0.052$ ) (Table 3$)$. The result for MCPyV differed according to glioma subtype (Supplemental Table S1): for GBM, ORs rose with increasing tertile (OR for tertile 3 vs seronegativity: 1.80 (95\% CI 1.03-3.15) with a significant trend ( $p$-value trend $=0.048$ ), whereas for nonGBM, the OR was significantly elevated only in the first tertile (OR for tertile 1 vs seronegativity: 2.11 (95\% CI 1.06-4.19) and declined with increasing tertile (OR for tertile 3 vs seronegativity:1.29 (95\% CI 0.59-2.81) with a nonsignificant trend ( $p$-value trend $=0.575$ ).

For MCPyV, ORs for all gliomas combined were more elevated with increasing length of time between blood collection and glioma diagnosis (ORs: 1.35 (95\% CI 0.76-2.41), 1.61 (95\% CI 0.89-2.90), and 1.75 (95\% CI $0.95-3.23)$, for $\leq 12.6$ years, $>12.6$ to $<18.5$ years, and $\geq 18.5$ years, respectively) and age at blood collection (ORs: 1.44 (95\% CI 0.76-2.72), 1.48 (95\% CI 0.94-2.34), and 2.14 (95\% CI 0.87-5.26), for $\leq 40$ years, $41-45$ years, 
and $>45$ years, respectively), though no individual OR was statistically significant. Infection with JCV, BKV and HPyV6 were unrelated to glioma risk regardless of elapsed time between blood collection and glioma diagnosis and subject age at blood collection. In Janus, blood samples were collected over a 20 year period (between 1972 and 1991) and results were similar for samples collected in the first half (i.e.,1972-1981) versus the second half (i.e., 1982-1991) of the interval for each of the $4 \mathrm{HPyVs}$ that we studied (Supplemental Table S2). For example, a positive association for MCPyV seroprevalence was demonstrated for the period from 1972 to 1981 (OR: 1.74; 95\% CI 0.99, 3.05; $\mathrm{p}=0.055$ ) and for the period from 1982 to 1991 (OR: 1.46; 95\% CI 0.95, 2.24; $\mathrm{p}=0.086$ ), though neither result was statistically significant in stratified analyses.

\section{Discussion}

This is the first large prospective study to examine JCV, BKV, MCPyV and HPyV6 as potential causal agents in glioma. We found no consistent evidence supporting a role for BKV, JCV or HPyV6. In contrast, infection with $\mathrm{MCPyV}$ was positively associated with the risk of glioma. In Janus, the association with MCPyV was observed regardless of glioma subtype and gender. To our knowledge, this is the first study to implicate MCPyV infection in the development of a CNS tumor in humans, following evidence that a phylogenetically closely related virus $(\mathrm{RacPyV})$ causes glioma-like tumors in raccoons ${ }^{29,47}$.

One previous prospective study ${ }^{31}$ based on a small set of incident cases ( 44 gliomas) examined glioma risk in relation to BKV and JCV infection. The authors reported a suggestive positive association with JCV and inverse association with BKV and findings that were more pronounced among GBMs (ORs of 2.38 and 0.53 , respectively). The current study yielded nonsignificant results for both BKV and JCV, consistent with a lack of conclusive evidence of a role for these viruses in the development of human tumors ${ }^{48}$.

The present findings for MCPyV are of interest in view of the established association of this virus with Merkel cell carcinoma (MCC), an aggressive neuroendocrine tumor of the skin ${ }^{28,49}$. The etiology of MCC has been linked to ultraviolet light (UV) exposure and to infection with MCPyV. The attributable risk of each exposure depends on geography: in northern latitudes, the majority of MCC cases are of viral etiology, whereas in areas with high UV exposure, more cases are related to UV-mediated carcinogenesis ${ }^{50}$. UV exposure is thought to be involved in both viral-mediated and non-viral-mediated carcinogenesis by contributing to immunosuppression or DNA damage, respectively. With the exception of our report, to our knowledge no other tumor in humans has been linked to MCPyV exposure.

A biologic mechanism linking MCPyV infection to the risk of glioma is unknown. Whereas MCPyV is not specifically known to cross the blood-brain-barrier ${ }^{14}$, other human PyVs such as JCV are known to do $\mathrm{so}^{26}$, as does $\mathrm{RaCPyV}^{29}$. In MCC, viral DNA is found integrated within the tumor genome in a clonal pattern suggesting that MCPyV infection and integration precede clonal expansion of tumor cells ${ }^{27}$. Whereas studies to date have not demonstrated MCPyV viral protein expression in human glial tumors ${ }^{51,52}$, MCPyV may contribute to glioma via a range of mechanisms ${ }^{16}$ such as neuroinflammation ${ }^{53,54}$, insertional mutagenesis ${ }^{55-57}$, or effects on gene expression $^{58}$ that would not leave traces of viral integration in the tumor genome. Of note, RacPyV is considered the causal agent of neuroglial olfactory tract tumors in free-ranging raccoons ${ }^{29}$; the virus has not been found integrated in tumor DNA, suggesting a mechanism of PyV-mediated oncogenesis not requiring direct host cell integration ${ }^{47}$. MCPyV is a latent infection that occurs most often in early childhood ${ }^{21,42}$ and lies dormant but may reactivate in the context of immunosuppression to cause disease (i.e. BKV-related nephropathy in transplant patients and JCV-related PML in AIDS patients); therefore, IgG capsid antibodies reflect infection occurring decades prior to blood collection. The present association of MCPyV with glioma, including the suggestion of increased risk with advancing age at blood collection in the Janus series, is consistent with reactivation of latent virus possibly triggered by immune senescence with advancing age ${ }^{59,60}$ contributing to glioma onset. Why a common exposure like MCPyV might lead to the development of glioma is unknown. However, it is notable that MCC is also a rare tumor caused by exposure to this virus. Furthermore, a similar pattern is observed for Epstein-Barr virus, a ubiquitous Herpesvirus that is considered a necessary cause of nasopharyngeal carcinoma and Burkitt lymphoma, which are both rare cancers ${ }^{61}$. The association between EBV and rare malignancies suggests that as-yet unknown co-factors influence host susceptibility to this virus ${ }^{62}$. Analogously, MCPyV may contribute to neuro-oncogenesis only in the presence of host immune or genetic co-factors, a hypothesis that should be examined in future studies.

A key strength of the present study was the prospective design and investigation of prediagnostic blood samples for detection of viral antibodies. In the Janus Serum Bank, glioma cases were diagnosed over a broad interval following blood collection (5-35 years, with a median of 15 years) allowing for examination of potential latency of viral exposures on glioma risk. Furthermore, all analytic cases were diagnosed presumably outside of the preclinical window ( 3 or more years following blood collection in CPS-II, and 5 or more years in Janus) reducing potential influence of preclinical tumor on viral markers.

We acknowledge several limitations. Power to detect associations by gender and according to latency and antibody titer, were limited in the Janus Serum Bank and these evaluations could not be performed in CPS-II due to small numbers. For the same reason, we were unable to examine associations according to specific lower grade glioma histologic subtypes in Janus. Furthermore, IDH1 mutation status, which is an important molecular classifier of low grade gliomas and secondary $\mathrm{GBM}^{63}$, was not available in either study to examine whether associations vary according to IDH1 status. Lack of a statistically significant association for MCPyV in CPS-II could be explained by the small number of incident glioma cases or potentially the older age at onset of glioma in CPS-II cases when compared to Janus cases, although data from Janus Serum Bank suggests if anything a stronger association of the virus with glioma in older persons. Blood samples were collected in some cases many years before serologic testing for $\mathrm{HPyV}$ antibodies and long storage times could potentially have affected assay results. However, we note that antibodies are considered robust biomolecules ${ }^{64}$ that are stable with prolonged 
storage periods at low temperatures (at or below $\left.-20^{\circ} \mathrm{C}\right)^{65}$. In our study, we were able to detect a range of values for all $\mathrm{HPyV}$ antibodies, suggesting that the titer distribution at the time of measurement reflected the titer range at blood draw ${ }^{40}$. Furthermore, in studies of $\mathrm{HPV}^{66}$, antibody titers have been shown to be comparable in serum samples from Janus versus other cohorts with shorter storage times; as HPV antibody titers after natural infection are much lower than for HPyV (and therefore less robust in serological assays), these results provide further assurance that long storage times did not affect the present results. We lacked information on lifestyle factors such as smoking and obesity which are known to impact immune surveillance ${ }^{67-72}$ and may confound or alter strength of associations between viruses and cancer. Immunity is known to wane with age $\mathrm{s}^{59,73}$ and we had a limited ability to consider associations according to age given the tight age distribution in the Janus Serum Bank. We also could not investigate associations by race/ethnicity. The study was based on a single blood measurement and infections that occurred after blood collection would have introduced misclassification of exposure; however, as studies have shown that seroprevalence of PyVs within individuals is stable over a decade or more in adults ${ }^{40}$, and that most individuals are infected with PyVs in childhood or adolescence ${ }^{21,42}$, we expect that misclassification of PyV infection status was limited among the middle aged adults in these cohorts. Finally, we did not consider antibodies to the viral T-antigens in $\mathrm{MCPyV}$ which are the key oncogenic drivers for $\mathrm{MCC}^{74}$; demonstation of a more prominent association of the T-antigen in MCPyV with glioma risk, as has been demonstrated in $\mathrm{MCC}^{74}$, would strengthen the case for a causal association.

In summary, in this pilot investigation we found the first evidence linking glioma risk specifically to infection with MCPyV but not with the 3 other PyVs examined. Investigations based on larger, diverse study populations with long-standing biorepositories are needed to clarify the role for MCPyV and other PyVs that infect humans $s^{21,43}$ as potential causal agents in glioma.

\section{Data availability}

For access to data from the Janus Serum Bank approval must be obtained from The Regional Ethics Committee of Southern Norway and from the Cancer Registry of Norway (in charge of the Janus Serum Bank), according to national and European regulations of data protection. Data underlying the CPSII-NC results are available upon request by following the procedures outlined here: https://www.cancer.org/content/dam/cancer-org/research/ epidemiology/cancer-prevention-study-data-access-policies.pdf

Received: 15 October 2020; Accepted: 16 April 2021

Published online: 05 May 2021

\section{References}

1. Ostrom, Q. T. et al. CBTRUS statistical report: Primary brain and other central nervous system tumors diagnosed in the United States in 2013-2017. Neuro Oncol. 22(12), 1-96. https://doi.org/10.1093/neuonc/noaa200 (2020) (Epub 2020/10/31).

2. Kohler, B. A. et al. Annual report to the nation on the status of cancer, 1975-2007, featuring tumors of the brain and other nervous system. J. Natl. Cancer Inst. 103(9), 714-736. https://doi.org/10.1093/jnci/djr077 (2011) (Epub 2011/04/02).

3. Rice, T. et al. Understanding inherited genetic risk of adult glioma: A review. Neurooncol. Pract. 3(1), 10-16. https://doi.org/10. 1093/nop/npv026 (2016) (Epub 2016/03/05)

4. Melin, B. S. et al. Genome-wide association study of glioma subtypes identifies specific differences in genetic susceptibility to glioblastoma and non-glioblastoma tumors. Nat. Genet. 49(5), 789-794. https://doi.org/10.1038/ng.3823 (2017).

5. Kitahara, C. M. et al. Association between adult height, genetic susceptibility and risk of glioma. Int. J. Epidemiol. 41(4), 1075-1085. https://doi.org/10.1093/ije/dys114 (2012) (Epub 2012/08/31).

6. Krishnamachari, B. et al. A pooled multisite analysis of the effects of female reproductive hormones on glioma risk. Cancer Causes Control. 25(8), 1007-1013. https://doi.org/10.1007/s10552-014-0400-8 (2014) (Epub 2014/06/04).

7. Braganza, M. Z. et al. Ionizing radiation and the risk of brain and central nervous system tumors: a systematic review. Neuro Oncol. 14(11), 1316-1324. https://doi.org/10.1093/neuonc/nos208 (2012) (Epub 2012/09/07).

8. Linos, E., Raine, T., Alonso, A. \& Michaud, D. Atopy and risk of brain tumors: A meta-analysis. J. Natl. Cancer Inst. 99(20), 1544-1550. https://doi.org/10.1093/jnci/djm170 (2007) (Epub 2007/10/11).

9. Cahoon, E. K., Inskip, P. D., Gridley, G. \& Brenner, A. V. Immune-related conditions and subsequent risk of brain cancer in a cohort of 4.5 million male US veterans. Br. J. Cancer 110(7), 1825-1833. https://doi.org/10.1038/bjc.2014.97 (2014).

10. Calboli, F. C. et al. Prediagnostic plasma IgE levels and risk of adult glioma in four prospective cohort studies. J. Natl. Cancer Inst. 103(21), 1588-1595. https://doi.org/10.1093/jnci/djr361 (2011) (Epub 2011/10/20).

11. Schlehofer, B. et al. Primary brain tumours and specific serum immunoglobulin E: A case-control study nested in the European Prospective Investigation into Cancer and Nutrition cohort. Allergy 66(11), 1434-1441. https://doi.org/10.1111/j.1398-9995.2011. 02670.x (2011) (Epub 2011/07/06).

12. Schwartzbaum, J. et al. Association between prediagnostic IgE levels and risk of glioma. J. Natl. Cancer Inst. 104(16), 1251-1259. https://doi.org/10.1093/jnci/djs315 (2012) (Epub 2012/08/03).

13. McFaline-Figueroa, J. R. \& Wen, P. Y. The Viral Connection to Glioblastoma. Curr. Infect. Dis. Rep. 19(2), 5. https://doi.org/10. 1007/s11908-017-0563-z (2017) (Epub 2017/02/25).

14. Michalicova, A., Bhide, K., Bhide, M. \& Kovac, A. How viruses infiltrate the central nervous system. Acta Virol. 61(4), 393-400. https://doi.org/10.4149/av_2017_401 (2017) (Epub 2017/12/01).

15. Perry, V. H., Cunningham, C. \& Holmes, C. Systemic infections and inflammation affect chronic neurodegeneration. Nat. Rev. Immunol. 7(2), 161-167. https://doi.org/10.1038/nri2015 (2007) (Epub 2007/01/16).

16. Amirian, E. S., Bondy, M. L., Mo, Q., Bainbridge, M. N. \& Scheurer, M. E. Presence of viral DNA in whole-genome sequencing of brain tumor tissues from the cancer genome atlas. J. Virol. 88(1), 774. https://doi.org/10.1128/jvi.02725-13 (2014) (Epub 2013/12/20)

17. Wrensch, M. et al. Does prior infection with varicella-zoster virus influence risk of adult glioma?. Am. J. Epidemiol. 145(7), 594-597. https://doi.org/10.1093/oxfordjournals.aje.a009155 (1997) (Epub 1997/04/01).

18. Wrensch, M. et al. History of chickenpox and shingles and prevalence of antibodies to varicella-zoster virus and three other herpesviruses among adults with glioma and controls. Am. J. Epidemiol. 161(10), 929-938. https://doi.org/10.1093/aje/kwi119 (2005) (Epub 2005/05/05).

19. Amirian, E. S. et al. History of chickenpox in glioma risk: A report from the glioma international case-control study (GICC). Cancer Med. 5(6), 1352-1358. https://doi.org/10.1002/cam4.682 (2016) (Epub 2005/05/05). 
20. Sheu, J. C. et al. Polyomaviruses of the skin: integrating molecular and clinical advances in an emerging class of viruses. $B r$. J. Dermatol. 180(6), 1302-1311. https://doi.org/10.1111/bjd.17592 (2019) (Epub 2018/12/27).

21. Kean, J. M., Rao, S., Wang, M. \& Garcea, R. L. Seroepidemiology of human polyomaviruses. PLoS Pathog. 5(3), e1000363. https:// doi.org/10.1371/journal.ppat.1000363 (2009) (Epub 2009/03/28).

22. DeCaprio, J. A. \& Garcea, R. L. A cornucopia of human polyomaviruses. Nat. Rev. Microbiol. 11(4), 264-276. https://doi.org/10. 1038/nrmicro2992 (2013) (Epub 2013/03/12).

23. Padgett, B. L., Walker, D. L., ZuRhein, G. M., Eckroade, R. J. \& Dessel, B. H. Cultivation of papova-like virus from human brain with progressive multifocal leucoencephalopathy. Lancet (London, England). 1(7712), 1257-1260. https://doi.org/10.1016/s01406736(71)91777-6 (1971) (Epub 1971/06/19).

24. Gardner, S. D., Field, A. M., Coleman, D. V. \& Hulme, B. New human papovavirus (BK) isolated from urine after renal transplantation. Lancet 1(7712), 1253-1257. https://doi.org/10.1016/s0140-6736(71)91776-4 (1971) (Epub 1971/06/19).

25. White, M. K. et al. Human polyomaviruses and brain tumors. Brain Res. Brain Res. Rev. 50(1), 69-85. https://doi.org/10.1016/j. brainresrev.2005.04.007 (2005) (Epub 2005/06/29)

26. Major, E. O., Yousry, T. A. \& Clifford, D. B. Pathogenesis of progressive multifocal leukoencephalopathy and risks associated with treatments for multiple sclerosis: A decade of lessons learned. Lancet Neurol. 17(5), 467-480. https://doi.org/10.1016/s14744422(18)30040-1 (2018) (Epub 2018/04/17).

27. Feng, H., Shuda, M., Chang, Y. \& Moore, P. S. Clonal integration of a polyomavirus in human Merkel cell carcinoma. Science (New York, NY). 319(5866), 1096-1100. https://doi.org/10.1126/science.1152586 (2008) (Epub 2008/01/19).

28. Becker, J. C. et al. Merkel cell carcinoma. Nat. Rev. Dis. Primers. 3, 17077. https://doi.org/10.1038/nrdp.2017.77 (2017) (Epub 2017/10/27).

29. Dela Cruz, F. N. \& Jr., Giannitti F, Li L, Woods LW, Del Valle L, Delwart E, Pesavento PA. ,. Novel polyomavirus associated with brain tumors in free-ranging raccoons, western United States. Emerg. Infect. Dis. 19(1), 77-84. https://doi.org/10.3201/eid1901. 121078 (2013) (Epub 2012/12/25).

30. Bouvard, V. et al. A review of human carcinogens-Part B: biological agents. Lancet Oncol. 10(4), 321-322. https://doi.org/10.1016/ s1470-2045(09)70096-8 (2009) (Epub 2009/04/08).

31. Rollison, D. E. et al. Serum antibodies to JC virus, BK virus, simian virus 40, and the risk of incident adult astrocytic brain tumors. Cancer Epidemiol. Biomarkers Prevent. 12(5), 460-463 (2003) (Epub 2003/05/17).

32. Calle, E. E. et al. The American Cancer Society Cancer Prevention Study II Nutrition Cohort: Rationale, study design, and baseline characteristics. Cancer 94(2), 500-511. https://doi.org/10.1002/cncr.10197 (2002) (Epub 2002/03/20).

33. Langseth, H., Gislefoss, R. E., Martinsen, J. I., Dillner, J. \& Ursin, G. Cohort profile: The Janus Serum Bank cohort in Norway. Int. J. Epidemiol. 46(2), 403-404. https://doi.org/10.1093/ije/dyw027 (2017) (Epub 2016/04/12).

34. Louis, D. N. et al. The 2007 WHO classification of tumours of the central nervous system. Acta Neuropathol. 114(2), 97-109. https://doi.org/10.1007/s00401-007-0243-4 (2007) (Epub 2007/07/10).

35. Ostrom, Q. T. et al. CBTRUS statistical report: Primary brain and other central nervous system tumors diagnosed in the United States in 2011-2015. Neuro Oncol. 20(4), 1-86. https://doi.org/10.1093/neuonc/noyl31 (2018) (Epub 2018/11/18).

36. Percy, C., Fritz, A., Jack, A., Shanmugarathan, S., Sobin, L., Parkin, D.M., Whelan, S. International Classification of diseases for oncology third ed: World Health Organization (2000).

37. Schwartzbaum, J. et al. A nested case-control study of 277 prediagnostic serum cytokines and glioma. PLoS ONE 12(6), e0178705. https://doi.org/10.1371/journal.pone.0178705 (2017) (Epub 2017/06/09).

38. Waterboer, T. et al. Multiplex human papillomavirus serology based on in situ-purified glutathione s-transferase fusion proteins. Clin. Chem. 51(10), 1845-1853. https://doi.org/10.1373/clinchem.2005.052381 (2005).

39. Kjaerheim, K. et al. Absence of SV40 antibodies or DNA fragments in prediagnostic mesothelioma serum samples. Int. J. Cancer 120(11), 2459-2465. https://doi.org/10.1002/ijc.22592 (2007) (Epub 2007/02/23).

40. Antonsson, A. et al. Prevalence and stability of antibodies to the BK and JC polyomaviruses: a long-term longitudinal study of Australians. J. Gen. Virol. 91(Pt 7), 1849-1853. https://doi.org/10.1099/vir.0.020115-0 (2010) (Epub 2010/03/12).

41. Gossai, A. et al. Seroepidemiology of human polyomaviruses in a US population. Am. J. Epidemiol. 183(1), 61-69. https://doi.org/ 10.1093/aje/kwv155 (2016) (Epub 2015/12/17).

42. Nicol, J. T. et al. Age-specific seroprevalences of merkel cell polyomavirus, human polyomaviruses 6, 7, and 9, and trichodysplasia spinulosa-associated polyomavirus. CVI. 20(3), 363-368. https://doi.org/10.1128/cvi.00438-12 (2013) (Epub 2013/01/11).

43. van der Meijden, E. et al. Different serologic behavior of MCPyV, TSPyV, HPyV6, HPyV7 and HPyV9 polyomaviruses found on the skin. PLoS ONE 8(11), e81078. https://doi.org/10.1371/journal.pone.0081078 (2013) (Epub 2013/11/28).

44. Sroller, V. et al. Seroprevalence rates of HPyV6, HPyV7, TSPyV, HPyV9, MWPyV and KIPyV polyomaviruses among the healthy blood donors. J. Med. Virol. 88(7), 1254-1261. https://doi.org/10.1002/jmv.24440 (2016) (Epub 2015/12/03).

45. Antonsson, A. et al. Prevalence and stability of antibodies to thirteen polyomaviruses and association with cutaneous squamous cell carcinoma: A population-based study. J. Clin. Virol. 101, 34-37. https://doi.org/10.1016/j.jcv.2018.01.013 (2018) (Epub 2018/02/08).

46. Kamminga, S., van der Meijden, E., Feltkamp, M. C. W. \& Zaaijer, H. L. Seroprevalence of fourteen human polyomaviruses determined in blood donors. PLOS ONE 13(10), e0206273. https://doi.org/10.1371/journal.pone.0206273 (2018) (Epub 2018/10/24).

47. Brostoff, T., Dela Cruz, F. N. \& Jr., Church ME, Woolard KD, Pesavento PA. ,. The raccoon polyomavirus genome and tumor antigen transcription are stable and abundant in neuroglial tumors. J. Virol. 88(21), 12816-12824. https://doi.org/10.1128/jvi.01912-14 (2014) (Epub 2014/08/29).

48. Levican, J., Acevedo, M., Leon, O., Gaggero, A. \& Aguayo, F. Role of BK human polyomavirus in cancer. Infect. Agents Cancer. 13, 12. https://doi.org/10.1186/s13027-018-0182-9 (2018) (Epub 2018/04/11).

49. Coggshall, K., Tello, T. L., North, J. P. \& Yu, S. S. Merkel cell carcinoma: An update and review: Pathogenesis, diagnosis, and staging. J. Am. Acad. Dermatol. 78(3), 433-442. https://doi.org/10.1016/j.jaad.2017.12.001 (2018) (Epub 2017/12/13).

50. Becker, J. C. et al. Merkel cell carcinoma. Nat. Rev. Dis. Primers. 3, 17077. https://doi.org/10.1038/nrdp.2017.77 (2017) (Epub 2017/10/27)

51. Khoury, J. D. et al. Landscape of DNA virus associations across human malignant cancers: Analysis of 3,775 cases using RNA-Seq. J. Virol. 87(16), 8916-8926. https://doi.org/10.1128/jvi.00340-13 (2013) (Epub 2013/06/07).

52. Strong, M. J. et al. A comprehensive next generation sequencing-based virome assessment in brain tissue suggests no major virus - tumor association. Acta Neuropathol. Commun. 4(1), 71. https://doi.org/10.1186/s40478-016-0338-z (2016) (Epub 2016/07/13).

53. Coussens, L. M. \& Werb, Z. Inflammation and cancer. Nature 420(6917), 860-867. https://doi.org/10.1038/nature01322 (2002) (Epub 2002/12/20).

54. Fitzpatrick, F. A. Inflammation, carcinogenesis and cancer. Int. Immunopharmacol. 1(9-10), 1651-1667 (2001) (Epub 2001/09/20).

55. Fan, H. \& Johnson, C. Insertional oncogenesis by non-acute retroviruses: Implications for gene therapy. Viruses 3(4), 398-422. https://doi.org/10.3390/v3040398 (2011) (Epub 2011/10/14).

56. Guerrieri, F., Belloni, L., Pediconi, N. \& Levrero, M. Molecular mechanisms of HBV-associated hepatocarcinogenesis. Semin. Liver Dis. 33(2), 147-156. https://doi.org/10.1055/s-0033-1345721 (2013) (Epub 2013/06/12).

57. Uren, A. G., Kool, J., Berns, A. \& van Lohuizen, M. Retroviral insertional mutagenesis: Past, present and future. Oncogene 24(52), 7656-7672. https://doi.org/10.1038/sj.onc.1209043 (2005) (Epub 2005/11/22). 
58. Kaneda, A., Matsusaka, K., Aburatani, H. \& Fukayama, M. Epstein-Barr virus infection as an epigenetic driver of tumorigenesis. Can. Res. 72(14), 3445-3450. https://doi.org/10.1158/0008-5472.Can-11-3919 (2012) (Epub 2012/07/05).

59. Goronzy, J. J. \& Weyand, C. M. Understanding immunosenescence to improve responses to vaccines. Nat. Immunol. 14(5), 428-436. https://doi.org/10.1038/ni.2588 (2013) (Epub 2013/04/20).

60. Nikolich-Žugich, J. The twilight of immunity: Emerging concepts in aging of the immune system. Nat. Immunol. 19(1), 10-19. https://doi.org/10.1038/s41590-017-0006-x (2018) (Epub 2017/12/16).

61. Bakkalci, D. et al. Risk factors for Epstein Barr virus-associated cancers: A systematic review, critical appraisal, and mapping of the epidemiological evidence. J. Glob. Health. 10(1), 405. https://doi.org/10.7189/jogh.10.010405 (2020) (Epub 2020/04/08).

62. Shannon-Lowe, C. \& Rickinson, A. The global landscape of EBV-associated tumors. Front Oncol. 9, 713. https://doi.org/10.3389/ fonc.2019.00713 (2019) (Epub 2019/08/27).

63. Waitkus, M. S., Diplas, B. H. \& Yan, H. Isocitrate dehydrogenase mutations in gliomas. Neuro Oncol. 18(1), 16-26. https://doi.org/ 10.1093/neuonc/nov136 (2016) (Epub 2015/07/19).

64. Hodgkinson, V. S. et al. Preanalytical stability of antibodies to pathogenic antigens. Cancer Epidemiol. Biomark. Prevent. 26(8), 1337-1344. https://doi.org/10.1158/1055-9965.Epi-17-0170 (2017) (Epub 2017/05/10).

65. Gislefoss, R. E., Grimsrud, T. K. \& Mørkrid, L. Stability of selected serum hormones and lipids after long-term storage in the Janus Serum Bank. Clin Biochem. 48(6), 364-369. https://doi.org/10.1016/j.clinbiochem.2014.12.006 (2015) (Epub 2014/12/20).

66. Kreimer, A. R. et al. Timing of HPV16-E6 antibody seroconversion before OPSCC: Findings from the HPVC3 consortium. Ann Oncol. 30(8), 1335-1343. https://doi.org/10.1093/annonc/mdz138 (2019) (Epub 2019/06/12)

67. Smoking and immunity. Lancet (London, England). 335(8705), 1561-1563 (1990) (Epub 1990/06/30).

68. de Heredia, F. P., Gomez-Martinez, S. \& Marcos, A. Obesity, inflammation and the immune system. Proc. Nutr. Soc. 71(2), 332-338. https://doi.org/10.1017/s0029665112000092 (2012) (Epub 2012/03/21).

69. Grant, R. W. \& Dixit, V. D. Adipose tissue as an immunological organ. Obesity (Silver Spring, Md). 23(3), 512-518. https://doi.org/ 10.1002/oby.21003 (2015) (Epub 2015/01/23).

70. McAllister-Sistilli, C. G. et al. The effects of nicotine on the immune system. Psychoneuroendocrinology 23(2), 175-187 (1998) (Epub 1998/06/11).

71. Sopori, M. Effects of cigarette smoke on the immune system. Nat. Rev. Immunol. 2(5), 372-377. https://doi.org/10.1038/nri803 (2002) (Epub 2002/05/30).

72. Sopori, M. L. \& Kozak, W. Immunomodulatory effects of cigarette smoke. J. Neuroimmunol. 83(1-2), 148-156 (1998) (Epub 1998/06/04).

73. Nikolich-Zugich, J. The twilight of immunity: emerging concepts in aging of the immune system. Nat Immunol. 19(1), 10-19. https://doi.org/10.1038/s41590-017-0006-x (2018) (Epub 2017/12/16).

74. Paulson, K. G. et al. Antibodies to merkel cell polyomavirus T antigen oncoproteins reflect tumor burden in merkel cell carcinoma patients. Can. Res. 70(21), 8388-8397. https://doi.org/10.1158/0008-5472.Can-10-2128 (2010) (Epub 2010/10/21).

\section{Acknowledgements}

The authors express sincere appreciation to all Cancer Prevention Study-II and Janus Serum Bank participants, and to each member of the American Cancer Society study and biospecimen management group. The authors would like to acknowledge the contribution to this study from central cancer registries supported through the Centers for Disease Control and Prevention's National Program of Cancer Registries and cancer registries supported by the National Cancer Institute's Surveillance Epidemiology and End Results Program. This work has been supported in part by the Biostatistics and Bioinformatics Shared Resource at the H. Lee Moffitt Cancer Center \& Research Institute, an NCI designated Comprehensive Cancer Center (P30-CA076292).

\section{Author contributions}

K.M.E and T.K.G conceived the study. Quality control of data and algorithms was provided by Y.K, N.B, J.M.H, T.K.G, and T.W. K.M.E wrote the draft manuscript and Y.K, N.B, J.M.H, A.E.C, S.A.SW, D.E.R, L.R.T, T.K.G, and T.W provided input at the writing stage. All authors reviewed and approved the final version of the manuscript.

\section{Funding}

The research was supported by a grant from the Center for Immunization and Infection Research in Cancer at the Moffitt Cancer Center. The American Cancer Society funds the creation, maintenance, and updating of the Cancer Prevention Study-II cohort.

\section{Competing interests}

The authors declare no competing interests.

\section{Additional information}

Supplementary Information The online version contains supplementary material available at https://doi.org/ 10.1038/s41598-021-89133-3.

Correspondence and requests for materials should be addressed to K.M.E.

Reprints and permissions information is available at www.nature.com/reprints.

Publisher's note Springer Nature remains neutral with regard to jurisdictional claims in published maps and institutional affiliations. 
(c) (i) Open Access This article is licensed under a Creative Commons Attribution 4.0 International cc) License, which permits use, sharing, adaptation, distribution and reproduction in any medium or format, as long as you give appropriate credit to the original author(s) and the source, provide a link to the Creative Commons licence, and indicate if changes were made. The images or other third party material in this article are included in the article's Creative Commons licence, unless indicated otherwise in a credit line to the material. If material is not included in the article's Creative Commons licence and your intended use is not permitted by statutory regulation or exceeds the permitted use, you will need to obtain permission directly from the copyright holder. To view a copy of this licence, visit http://creativecommons.org/licenses/by/4.0/.

(C) The Author(s) 2021 